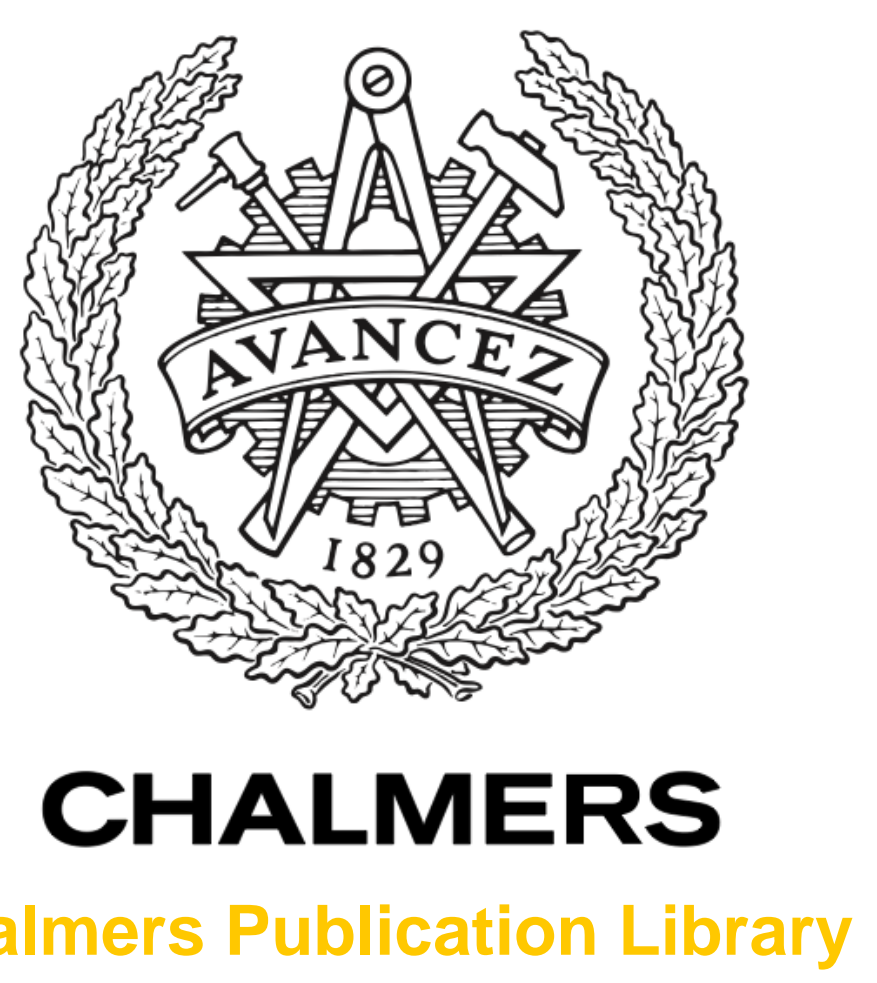

Challmers Publication Library

SF Box - A tool for evaluating the effects on soil functions in remediation projects

This document has been downloaded from Chalmers Publication Library (CPL). It is the author's version of a work that was accepted for publication in:

Integrated Environmental Assessment and Management (ISSN: 1551-3793)

Citation for the published paper:

Volchko, Y. ; Norrman, J. ; Rosén, L. et al. (2014) "SF Box - A tool for evaluating the effects on soil functions in remediation projects". Integrated Environmental Assessment and

Management, vol. 10(4), pp. 566-575.

http://dx.doi.org/10.1002/ieam.1552

Downloaded from: http://publications.lib.chalmers.se/publication/201580

Notice: Changes introduced as a result of publishing processes such as copy-editing and formatting may not be reflected in this document. For a definitive version of this work, please refer to the published source. Please note that access to the published version might require a subscription.

Chalmers Publication Library (CPL) offers the possibility of retrieving research publications produced at Chalmers University of Technology. It covers all types of publications: articles, dissertations, licentiate theses, masters theses, conference papers, reports etc. Since 2006 it is the official tool for Chalmers official publication statistics. To ensure that Chalmers research results are disseminated as widely as possible, an Open Access Policy has been adopted.

The CPL service is administrated and maintained by Chalmers Library. 
Revised manuscript 20140519

\section{SF Box - a Tool for Evaluating the Effects on Soil Functions in Remediation Projects}

Yevheniya Volchko*†, Jenny Norrman $†$, Lars Rosén $†$, Tommy Norberg $\ddagger$

†Department of Civil and Environmental Engineering, Chalmers University of Technology, SE-412 96 Gothenburg, Sweden

¥Mathematical Sciences, Chalmers University of Technology \& University of Gothenburg, SE-412 96 Gothenburg, Sweden

*To whom correspondence may be addressed:

volchko@chalmers.se 
Revised manuscript 20140519

\begin{abstract}
Although remediation is usually aimed at reducing the risks posed by contaminants to human health and the environment, it is also desirable that the remediated soil within future green spaces is capable of providing relevant ecological functions, e.g. basis for primary production. While addressing a contamination problem by reducing contaminant concentration/amounts in the soil, the remedial action itself can lead to soil structure disturbances, decline in organic matter and nutrient deficiencies, and in turn affect a soil's capacity to carry out its ecological soil functions. This paper presents the SF Box (Soil Function Box) tool that is aimed to facilitate integration of information from suggested soil quality indicators (SQIs) into a management process in remediation using a scoring method. The scored SQIs are integrated into a soil quality index corresponding to one of five classes. SF Box is applied on two cases from Sweden (Kvillebäcken and Hexion), explicitly taking into consideration uncertainties in the results by means of Monte Carlo simulations. At both sites the generated soil quality indices corresponded to a medium soil performance (soil class 3 ) with a high certainty. The main soil constraints at both Kvillebäcken and Hexion were associated with biological activity in the soil, as soil organisms were unable to supply plant-available nitrogen. At the Kvillebäcken site the top layer had a content of coarse fragment ( $\varnothing>2 \mathrm{~mm})$ higher than $35 \%$, indicating plant rooting limitations. At the Hexion site, the soil had limited amount of organic matter, thus poor aggregate stability and nutrient cycling potential. In contrast, the soil at Kvillebäcken was rich in organic matter. The soils at both sites were capable to store a sufficient amount of water for soil organisms between precipitations.
\end{abstract}

Keywords: soil quality indicators, soil quality index, soil functions, remediation, contaminated sites/soil 
Revised manuscript 20140519

\section{INTRODUCTION}

Contamination is a widespread threat to soil throughout the world. The soil quality standards for protection of the soil environment are based on guideline values which are usually derived from Species Sensitivity Distribution (SSD) models reflecting a dose-effect relationship for the selected species in ecotoxicity tests (Burgman 2005; Posthuma and Suter 2011). These tests, however, do not account for soil functions (e.g. basis for biodiversity, basis for primary production) relevant for future green areas of remediation sites. The emerging regulatory requirements on soil protection demand a more holistic and stringent soil assessment in soil remediation projects (Bone et al. 2010).

For the base case scenario the effects of contaminants on soil functions, e.g. organic matter degradation, recycling of nutrients, water cycling, formation of soil structure, biodiversity, can be evaluated using the Triad approach to ecological risk assessment (Semenzin et al. 2009). This approach simultaneously considers chemical concentrations, bioavailability of pollutants, ecotoxicity and ecology (Semenzin et al. 2009; Dagnino et al. 2008; Karjalainen et al. 2009). The ecology part of the Triad approach links the species to the processes and functions they mediate. If a particular species is affected by contaminants, the corresponding functions and processes are also considered to be impaired. Biodiversity indices are suggested to be used accounting for species richness, composition and evenness in the contaminated soil capturing biodiversity function (Semenzin et al. 2009).

It is generally assumed that remediation will not only reduce contaminant concentrations/amounts in the soil, but also restore ecological soil functions (Swedish EPA 1996). However, research results show that some remediation techniques can lead to soil structure disturbances, decline in organic matter, and nutrient deficiencies (e.g. Dawson et al. 2007; Makino et al. 2007; Pazos et al. 2012), in turn affecting a soil's potential to carry out its ecological functions associated with primary production. The SF Box tool may facilitate 
Revised manuscript 20140519

integration of information on these soil functions into the management process of remediation projects and is seen as being complementary to ecological risk assessment. First, the paper provides a background to the study by describing the SCORE (Sustainable Choice Of REmediation) tool which was developed for sustainability appraisal of remediation alternatives using Multi Criteria Decision Analysis (MCDA). Thereafter, the paper details a generic framework for soil function assessment in remediation projects. Further, the overall input/output flow in SF Box, which was developed in the context of the SCORE tool, is presented followed by description of scoring curves for soil function assessment and soil classification. Examples are then provided of two practical applications of SF Box in Sweden, explicitly taking into consideration uncertainties in the results. Finally, the study results are discussed and conclusions are drawn.

\section{BACKGROUND}

SF Box is a module of the SCORE tool. SCORE was developed for sustainability appraisal of remediation alternatives (Rosén et al. 2013). The tool is based on a MCDA framework capturing environmental, socio-cultural and economic criteria (Table 1).

The SCORE tool is aimed at evaluating changes (effects) as a result of a remedial action relative to the reference alternative (e.g. no action is taken). The social profitability criterion of the economic domain is addressed with a Cost-Benefit Analysis. The effects in the environmental and the socio-cultural domains are scored as follows: Very positive effect: +6 to +10 ; Positive effect: +1 to +5 ; No effect: 0 ; Negative effect: -1 to -5 ; Very negative effect: 6 to -10 . A normalized sustainability index is calculated for each alternative by aggregation of the scores in the three domains using a linear-additive method. Criteria of all three sustainability domains are evaluated with respect to effects on-site and off-site as well as effects due to reduction in source contamination and due to the remedial activity itself. 
Revised manuscript 20140519

SCORE further analyses the trade-offs between criteria determining whether a strong performance on one criterion is compensated by a weaker performance on another one.

The Soil criterion is an important aspect in sustainability appraisal of remediation alternatives. In SCORE, this criterion consists of two sub-criteria: (1) Ecotoxicological Risks and (2) Soil Functions, addressing the effects of remediation alternatives on the soil environment relative to a reference alternative. In this paper, the focus is made on soil function assessment within SCORE. The presented soil function assessment is meant to complement the ecological risk assessment.

\section{GENERIC FRAMEWORK FOR SOIL FUNCTION ASSESSMENT}

The suggested method for soil function assessment includes six steps: (1) selection of a minimum data set consisting of physical, chemical and biological indicators; (2) scoring of soil quality indicators; (3) calculation of soil quality index; (4) classification of the soil into soil classes; (5) uncertainty analysis, and (6) evaluation of the effects on soil classes relative to a soil class in the reference alternative (Figure 1).

Different sets of soil quality indicators (SQIs) can be used to evaluate different soil functions. The minimum data set (MDS) for assessment of soil functions associated with primary production is presented in Table 2 and derived based on studies exploring the effects on ecological soil functions in remediation projects (Brown et al. 2005; van Herwijen et al. 2007; Epelde et al. 2008a,b; 2009; 2010a,b; Doni et al. 2012; Pazos et al. 2012; Jelusic et al. 2013). The suggested MDS was identified by compiling SQIs that are (1) suggested by three or more of the literature sources, and (2) consistent with the MDSs for the purposes other than agricultural productivity of land (Bone et al. 2010; Craul and Craul 2006; Lehmann et al. 2008; Schindelbeck et al. 2008). 
Revised manuscript 20140519

The $\mathrm{NH}_{4}-\mathrm{N}$ concentration determined with a distillation method is used in this study as a proxy of biological activity for nitrogen in the soil. For example, Sharifi et al. (2007) suggested using the $\mathrm{NH}_{4}-\mathrm{N}$ concentration for predicting mineralizable $\mathrm{N}$ in the soil. Strong linear relationships between potentially mineralizable nitrogen and the $\mathrm{NH}_{4}-\mathrm{N}$ concentrations determined with the distillation method were reported in Bushong et al. (2008).

\section{THE SF BOX MODULE}

\section{Input/output flow}

The overall input/output flow in the SF Box module is presented in Figure 2. Contents of clay, silt and sand are used to determine soil texture (ST) using the Food and Agriculture of United Nations (FAO) triangle (FAO 2006). Content of coarse material (CM) is equal to the gravel content. Further, available water capacity (AW) is determined from the pore volume estimations of mineral soils using ST, organic matter content (OM) and bulk density (BD) (Lehmann et al. 2008). Using the scoring method, the sub-scores are computed for the SQIs from MDS presented in Table 2. AW, OM, potentially mineralizable nitrogen $\left(\mathrm{NH}_{4}-\mathrm{N}\right)$ and available phosphorus (P) are scored differently for coarse-, medium- and fine-textured materials (Figure 3). Coarse-textured materials are sand, sand, loamy sand, sandy loam. Medium-textured materials are loam, silt loam, silt, sandy clay loam. Fine-textured materials are clayey loam, silty clayey loam, sandy clay, silty clay, clay (Gugino et al., 2009). Further, the soil is classified based on the soil quality index which is an integration of the sub-scores. A technical description of a preliminary version can be found in Volchko (2013).

\section{Scoring curves}

The effects on soil functions are evaluated using the scoring approach described by Andrews et al. (2004), Gugino et al. (2009), Idowu et al. (2008), Schindelbeck et al. (2008) 
Revised manuscript 20140519

and Volchko (2013). First, the sub-scores for $\mathrm{CM}, \mathrm{AW}, \mathrm{OM}, \mathrm{NH}_{4}-\mathrm{N}$ and $\mathrm{P}$ are computed using three types of scoring functions: "more is better", "optimum" and "less is better". For the "more is better" example, the higher the value of soil quality indicator the higher the performance score of this indicator (see Figure 3b). For the "less is better" example, the lower the value of the soil quality indicator the higher the performance score (see Figure 3 a). For the "optimum" example, there is a limited range of values corresponding to a high score, whereas "less" and "more" than these optimum values are scored lower (see Figure 3 e).

The scoring functions transform input values of SQIs into fractional numbers between 0 and 1, where the intervals $[0 ; 0.30],[0.31 ; 0.7],[0.71 ; 1]$ represent poor, medium and good soil qualities, respectively. For example, 10\% of CM would be transformed by a scoring function into sub-score of 0.93 corresponding to "good soil quality" (Figure 3 a). OM of $2 \%$ would be transformed by another relevant scoring function into sub-score of 0.23 corresponding to "poor soil quality" (Figure $3 \mathrm{c}$ ).

Using an approximation method (goodness-of-fit; Grapher ${ }^{\mathrm{TM}}$ software, 2009), scoring functions for SQIs were determined (Figure 3; see also supplementary material) based on literature data (Table 3). The objective was to make the approximation as close as possible to the actual function describing the relationship between the measured value of SQI and a soil performance (sub-score).

In SF Box, a functionality was developed for $\mathrm{NH}_{4}-\mathrm{N}$ and $\mathrm{P}$ to provide the practitioner with some flexibility on selection among standard methods used for laboratory analysis of these SQIs. The scoring functions were developed for each analysis method. Two scoring curves were developed, 1) for potentially mineralizable nitrogen and 2) for the NH4-N concentration determined with the distillation method. The latter is presented in Figure $3(d)$. Two scoring functions were developed for vegetation favoring neutral and acidic $\mathrm{pH}$ (Figure 3 e). 
Revised manuscript 20140519

\section{Soil classification}

For integrating information from soil quality indicators into the management decision process, all sub-scores are integrated into a soil quality index using the arithmetic mean as suggested by Andrews et al. (2004):

$$
I=\frac{\sum_{i=1}^{n} S Q I_{i}}{n},
$$

where $I$ - soil quality index, $S Q I-$ i:th soil quality indicator, $n$ - the number of SQIs.

Other methods for aggregation of the sub-scores, i.e. computation of quadratic mean and geometric mean, can also be selected in SF Box.

The soil quality index forms a basis for soil classification into five soil classes corresponding to very good, good, medium, poor and very poor soil performances (Table 4).

\section{Uncertainty analysis}

The uncertainties in the predicted soil class result from spatial heterogeneity of SQIs, a limited sampling size, and analytical errors. Being an Excel-based tool, SF Box allows for uncertainty and sensitivity analyses with the Oracle ${ }^{\circledR}$ Crystal Ball add-in software. The uncertainties in the resulting soil quality index and the soil class are handled by assigning probability distributions to the SQIs in the scoring model and running a Monte Carlo simulation (MCS). MCS is a technique that randomly and repeatedly picks values from the probability distributions for each uncertain variable in the model in order to provide estimates of the likelihoods of different outcomes (Bedford and Cooke 2009). The sensitivity analysis is performed to investigate the contribution from each input variable, i.e. SQIs, to the total uncertainty in the soil quality index and the soil class. 
Revised manuscript 20140519

Assuming that all SQIs are normally distributed and accounting for sample size, translated and scaled $t$-distributions are used to represent the uncertainties of the mean value of each SQI. The parameters of the $t$-distribution are the mean value of the SQI, the scale $\left(\frac{s}{\sqrt{n}}\right)$, and the degrees of freedom $(n-1)$, where $s$ is the standard deviation and $n$ is the number of soil samples (Gelman et al. 2004). The normality assumption is based on data analysis with the ProUCL4.0 software for the Hexion and the Kvillebäcken sites (see case description below). Since BD is represented by five discrete values ranging between 1 to $1.8 \mathrm{~g} / \mathrm{cm}^{3}$ in accordance with the table for determination of the pore volume of mineral soils (Lehmann 2008), a discrete custom probability distribution is used to represent the uncertainty in this SQI.

\section{CASE STUDIES}

\section{Hexion}

The Hexion site is located in Mölndal, south of Gothenburg, the western part of Sweden. Hexion is a former industrial site, with a former paint factory producing chemicals and binding agents. The industrial activities lasted from the 1940s until 2007. After remediation, the site is planned to be used for apartment blocks, school and preschool, shops and offices, traffic areas and parking lots and green areas with playing grounds.

Hexion is situated in the Gothenburg terminal moraine deposit. The soil deposits have a complex composition with varying fraction distribution, from well-sorted sand and gravel to glacial till with lenses of finer grains. The depth of the soil is generally 5-15 meter with glacial till closest to the bedrock, followed upwards by sand, gravel and silt (for details see Landström and Östlund, 2011). As a result of the long history of industrial activity there are large amounts of filling materials on top of the natural deposits. The filling material mostly consists of sand, gravel, bricks and asphalt (NCC Teknik 2010). 
Revised manuscript 20140519

The ground water flows 2-10 m below the surface in a north-south direction. The groundwater is artesian forming a spring in the steep slope of the Hexion site. The ground water connects to the river Mölndalsån, which runs south-east of the site. High flows and the erosional environment in the river beds prevent accumulation of contaminants in the sediments near the site. The risk posed by the contaminants at the site to the receptors in the River Mölndalsån is considered to be low (Sweco 2009).

There are parts of the area where the earlier activities have caused substantial contamination of both soil and groundwater, primarily by phthalates, lead and solvents. The contaminants are mostly found in the upper soil layers $(0-1 \mathrm{~m})$ but within limited parts of the area, high concentrations of specific contaminants have been found at greater depths.

Exposure pathways for humans with the future land use (as described above) are in the form of oral intake of contaminated soil, direct skin contact with contaminated soil, and inhalation of dust originating from contaminated soil. The results of the site-specific risk assessment show that exposure to volatile contaminants beneath the new buildings is not regarded to be an issue because the constructions will be sealed preventing volatiles from entering the buildings. There is a need to reduce the human health risks, and the risks for the environment (the upper soil layers and deep soil layers in limited parts of the area).

\section{Kvillebäcken}

The Kvillebäcken site is situated in Gothenburg, south-west Sweden. It is a former industrial site with small industries and other related activities. Eastern Kvillebäcken, which is a part of the redevelopment of a larger area, will primarily be developed into a residential area, with multi-family dwellings and such elements as retail premises, kindergartens, club rooms and the like. One part of the redevelopment area, in the vicinity of the residential area, is going to be turned into a green area. This area is located along the Kvillebäcken stream. 
Revised manuscript 20140519

The superficial soil layers in the Kvillebäcken area consists of filling material with a variable thickness, over $2 \mathrm{~m}$ in Eastern Kvillebäcken and about 0.3- $0.5 \mathrm{~m}$ in the western part. Below the filling material is glacial marine clay with a thickness of about $30-40 \mathrm{~m}$, which is situated directly on rock, sometimes with a thin layer of glacial till between the clay and the rock. Groundwater appears in the lower part of the filling material, on top of the sealing clay, or in the dry clay crust. The general groundwater flow direction is east towards the Kvillebäcken stream. Locally, pipes and pipe trenches greatly affect the flow direction.

Several environmental soil investigations have been carried out in the area. The studies show that soil is contaminated by past activities to a varying degree. High to very high concentrations of metals, aliphatic and aromatic hydrocarbons and PAHs have been detected in soil samples. Groundwater samplings show that despite high levels of pollutants in the soil, generally no contaminants, metals or organic substances, are found in the groundwater. The effects of pollutants on soil layers from previous activities primarily concern the filling material, although the underlying clay in occasional points has also been impacted in superficial parts in some locations.

Leaching tests for metals taken at the Kvillebäcken site have been performed on a collection of samples representing different filling materials. The concentrations at different ratios between liquid and solid material (L/S) were compared to the Swedish EPA's criteria for waste disposal. The concentrations of all investigated parameters are below the criteria for inert waste, with an exception for the fluoride content, which is slightly higher than the corresponding threshold (NCC Teknik 2000).

\section{Soil sampling and analysis}

At the Hexion site the soil was randomly sampled at two depths: $0-0.2 \mathrm{~m}$ and $0.2-0.5 \mathrm{~m}$ within the "green" area. At the Kvillebäcken site the soil within future park area was sampled 
regularly with an approximate sample separation of $25 \mathrm{~m}$ to depths of $0-0.2 \mathrm{~m}$ and $0.2-0.5 \mathrm{~m}$ along a line parallel to the stream (see plan in supplementary material). Sixteen soil samples were collected in total at each site. After being oven-burned at $550^{\circ} \mathrm{C}$, the soil was sieved to analyze particle size distribution (ISO 3310-2). The organic matter content was determined using a loss on ignition method (SS-EN 12879). The $\mathrm{NH}_{4}-\mathrm{N}$ concentration was analyzed by distilling the sample with a sodium hydroxide solution prior to titration with hydrochloric acid (APHA 1992). pH was determined using a glass electrode in a 1:5 (volume fraction) suspension of soil in water (ISO 10390). Available phosphorus extracted with ammonium lactate was quantified using inductively coupled plasma (ICP) spectrometry (the AL-P method; Egner et al. 1960; SS 02 8310). Available water capacity was determined indirectly as a function of soil texture, organic matter and bulk density (Lehmann et al., 2008) assuming that bulk density equals to $1.6 \mathrm{~g} \mathrm{~cm}^{-3}$.

\section{Results}

The soil function assessment results for the Hexion and the Kvillebäcken sites are presented in the SF Box spreadsheet model shown in Figure 4 and Figure 5 respectively. According to the FAO soil texture triangle (FAO 2006), the soils at Hexion Kvillebäcken site of varying soil texture ranging from silty loam to sand. The sub-scores are reported in columns $\mathrm{K}, \mathrm{M}, \mathrm{O}$, Q, S, and U of the SF Box spreadsheet model and highlighted with help of green-yellow-red colors corresponding to good-medium-poor soil qualities respectively (Figure 4 and Figure 5). Since all the sub-score cells for $\mathrm{NH}_{4}-\mathrm{N}$ (except of samples $0 \_0$ and $2 \_0$ at the Kvillebäcken site) are colored in light red (column S of the spreadsheet model; Figure 4 and Figure 5), soil constraints associated with biological activity at both sites can readily be identified. For all soil samples (except of sample 5_0 at the Kvillebäcken site; Figure 5 a) the high sub-scores are generated for AW at both sites. All the sub-scores for each soil sample are thereafter 
Revised manuscript 20140519

integrated into a soil quality index corresponding to a soil performance (columns $\mathrm{V}$ and $\mathrm{W}$ of the spreadsheet model in Figure 4 and Figure 5). Finally, a resulting soil class of 3 (medium soil performance) is computed for the green area at both the Hexion and the Kvillebäcken (cell W60 of the spreadsheet model; Figure 4 and Figure 5 respectively).

Monte Carlo analysis was performed using 10000 runs, providing probabilities of the five possible soil classes at Hexion and Kvillebäcken (see supplementary material). With more than $70 \%$ certainty, all sampled soils corresponds to soil class 3 and a medium soil performance.

In order to know how a given SQI affects the soil class, a sensitivity analysis was performed with Oracle ${ }^{\odot}$ Crystal Ball (see supplementary material). The sensitivity is calculated by computing correlation coefficients between each SQI and the resulting soil class. The positive coefficient indicates that the higher the index value of the SQI the higher the soil class (where class 1 is the best and class 5 is the poorest; Table 4 ), thus the better soil performance. In contrast, the negative coefficient indicates that the higher the value of the SQI the lower the resulting soil class, thus the poorer soil performance. The sensitivity analysis results show that $\mathrm{OM}$ and $\mathrm{pH}$ contribute most to the uncertainties in the resulting soil classes for the Hexion and the Kvillebäcken sites respectively.

\section{DISCUSSION AND CONCLUDING REMARKS}

\section{SF Box}

The SF Box tool integrates information from different SQIs into the management decision process enabling managers of contaminated land to evaluate the effects of remediation alternatives on ecological soil functions as a part of sustainability appraisal. The soil assessment in the tool is however limited to soil functions associated with primary production. In order to assess a biodiversity function, another set of SQIs and scoring curves should be developed, e.g. biodiversity indices can be used as suggested by Semenzin et al. 
Revised manuscript 20140519

(2009). Another constraint of the tool is associated with AW. This SQI is computed as a function of ST, OM and BD. The model only uses five discrete BD values between 1 and 1.8 $\mathrm{g} / \mathrm{cm}^{3}$ in order to derive AW, which is a limitation of the tool. A more advanced method for AW determination would require interpolation of the AW values for the intermediate BD values. The scoring functions for $\mathrm{AW}, \mathrm{OM}, \mathrm{NH}_{4}-\mathrm{N}$ and $\mathrm{pH}$ were derived from the statistical models developed for vegetable and crop production (Gugino et al., 2009). The data used for modelling was collected across the North-eastern United States. The thresholds for American and Swedish soils as well as other land uses may differ. It is assumed that the threshold values developed for crop production systems and used for determination of scoring functions in this study are applicable to a grass field use of remediation sites. Furthermore, in the developed scoring models the highest scores are assigned to the measured SQI values reflecting the full potential of the "ideal" soil to carry out its functions associated with primary production. However, in reality the full potential may differ for different types of soils. Validation of the scoring curves for Swedish soils and different types of soil is a priority for future refining of the presented method. This study has however focused on the operationalization of the method.

Although the suggested method for soil function assessment is generalized and somewhat simplified, it can provide practitioners with comprehensible information on basic soil properties with regard to soil functions relevant to the green areas of remediation sites as a complement to ecological risk assessment. To the advantage of the manager of contaminated sites, the tool provides:

- Color visualization of outputs.

Identification of soil function performances as well as sub-scores with different colors helps the practitioner (usually not familiar with different SQIs) to readily interpret the results saving time and efforts. 
Revised manuscript 20140519

- Flexibility.

The dropdown menus provide the practitioner with some flexibility on selection among standard methods (1) used for laboratory analysis of the SQIs, and (2) to be applied for computation of the soil quality index.

- Monte Carlo simulation opportunities.

Being an Excel-based tool, SF Box allows for uncertainly analysis of the obtained results using Monte Carlo simulations provided by the Oracle Crystal Ball ${ }^{\odot}$ software.

\section{Case studies}

SF Box was applied on two cases from Sweden. The soil quality indices computed for the green area at Hexion and for the future park area at Kvillebäcken corresponded to soil class 3 and medium soil performance (Figure 4 and Figure 5 respectively). The low sub-scores for $\mathrm{NH}_{4}-\mathrm{N}$ (see column $\mathrm{S}$ in the spreadsheet models; Figure 4 and Figure 5) indicated low biological activity in the soil and inability of soil organisms to support plant-available nitrogen. The low sub-scores for $\mathrm{CM}$ in the top layer at Kvillebäcken indicated an increased coarse fraction content that may lead to plant rooting limitations (see column $\mathrm{K}$ of the spreadsheet model; Figure 5a). In contrast, high sub-scores for OM at Kvillebäcken indicated that the soil is rich in organic matter, thus having a good water storage and nutrient cycling potential. The high sub-scores for AW at both sites indicated that the soil is capable to store a sufficient amount of water in the soil for soil organisms between precipitations (see column $\mathrm{O}$ of the spreadsheet models; Figure 4 and Figure 5).

The parameter uncertainties in SF Box were handled with Monte Carlo simulations using the Oracle Crystal Ballo software. The uncertainty analysis results show that the soil quality index corresponded to class 3 (medium soil performance) with a high certainty (see supplementary material) when the sub-scores were aggregated as arithmetic mean. Although 
the arithmetic mean is suggested for aggregation of the sub-scores (Andrews et al. 2004), the SF Box tool provides the possibility to select other methods to derive a soil quality index. For the Hexion site, when the sub-scores were aggregated using a geometric mean, the mean of the simulated soil quality index corresponded to a poor soil performance (Figure 6). Furthermore, the simulated soil quality index for the Kvillebäcken site was associated with more uncertainties when the sub-scores were aggregated using a geometric mean. In contrast to the arithmetic mean, the geometric mean does not allow for compensation of a strong performance on one SQI by a weaker performance on another one. Selection of the method for aggregation will have a large impact on the results.

The last step of the soil function assessment as outlined in Figure 1 is carried out in the SCORE tool for sustainability assessment, where the effects of remediation alternatives on soil functions are scored relative to the soil class computed for the reference alternative. In case of excavation, if contaminated soil within the future green area of class 3 will be substituted with a clean soil of higher soil classes, the effects on ecological soil functions associated with primary production will be positive. These higher soil classes imply that the soil is rich in organic matter, has sufficient amount of nutrients (e.g. phosphorus and plantavailable nitrogen) and a low content of coarse fractions. However, if the contaminated soil will be replaced with a clean soil of lower soil classes, i.e. soils with nutrient deficiencies and a high content of coarse material, the effects of remediation on ecological soil functions associated with primary production will be negative.

\section{Decision support}

The Soil criterion in the SCORE tool for sustainability appraisal of remediation alternatives addresses the effects associated with both ecotoxicological risks and soil functions. Thus, the results generated by the SF Box tool are seen as being complementary to 
Revised manuscript 20140519

ecological risk assessment. Usually, ecological risks assessment is based on guideline values derived from SSD models reflecting exposure of species under laboratory conditions. However, lab-to-field extrapolation of the SSD data can be misleading, because exposure conditions in the field and laboratory assays can significantly differ (Swartjes et al. 2012). For this reason the guideline value should rather serve as a marker for identification of the sites for further ecotoxicity studies. The Triad approach to ecological risk assessment is therefore suggested in order to combine contaminant concentrations, ecotoxicity and effects on a biodiversity function (e.g. Semenzin et al. 2009; Sorvari et al. 2013). Admittedly, although soil functions associated with primary production and biodiversity can be assessed for the base case scenario, it is difficult to predict the effects of remediation technologies on these functions when evaluating remediation alternatives. There is a lack of studies which are aimed at exploring the effects of remediation on a soil's capacity to carry out its ecological functions (Volchko et al. 2013). Still, soil functions should be considered in a management process of remediation projects, because it is important not only to reduce the risks posed by contaminants to a soil biota but also to ensure reestablishment of favorable conditions in the remediated soil enabling the biota to operate.

Being in line with the emerging regulatory requirements on soil protection, the SF Box tool facilitates integration of information from the suggested SQIs into the management decision process in remediation projects. Although the information from SQIs is intended to provide input for sustainability appraisal of remediation alternatives, it can also be used by practitioners for developing remediation strategies. If the soil has potentially favorable conditions for providing ecological soil functions, e.g. a limited content of coarse fragments and sufficient amounts of water and nutrients for soil organisms, alternative remediation strategies can be considered, e.g. the risks posed by contaminants in the soil can be reduced 
Revised manuscript 20140519

using biological treatment. However, other important factors should also be considered, e.g. bioavailability and mobility of pollutants in the soil, time aspects, and public acceptance.

\section{ACKNOWLEDGEMENTS}

The authors acknowledge the SNOWMAN Network, the Swedish EPA (Dnr 09/287) and the Swedish Research Council Formas (Dnr 242-2009-781) for financial support.

\section{REFERENCES}

Andrews SS, Karlen DL, Cambardella CA. 2004. The soil management assessment Formatted: English (U.S.) framework: a quantitative soil quality evaluation method. Soil Sci. Soc. Am. J. 68: 19451962.

[APHA] American Public Health Association. 1992. Standard Methods: For the Examination of Water and Wastewater, $18^{\text {th }}$ ed. Washington, USA: American Public Health Association.

Bedford T, Cooke R. 2009. Probabalistic Risk Analysis: Foundations and Methods. , NewYork, USA: Cambridge University Press. 393p.

Bone J, Head M, Barraclough D, Archer M, Scheib C, Flight D, Voulvoulis N. 2010. Soil quality assessment under emerging regulatory requirements. Environment International 36: 609-622.

Brown S, Sprenger M, Maxemchuk A, Compton H.2005. Ecosystem Function in Alluvial Tailings after Biosolids and Lime Addition. Journal of Environmental Quality 34: 139_148.

Burgman M. 2005. Risk and decision for conservation and environmental management. UK: Cambridge University Press. 488p.

Bushong JY, Roberts TL, Ross WJ, Norman RJ, Slaton NA, Wilson CE. 2008. Evaluation of distillation and diffusion techniques for estimating hydrolysable amino sugar-nitrogen as 
Revised manuscript 20140519

a means of predicting nitrogen mineralization. Soil Science Society of America Journal 72: 992-999.

Craul TA, Craul PJ. 2006. Soil Design Protocols for Landscape Architects and Contractors. New Jersey, USA: John Wiley and Sons. 339p.

Dagnino A, Sforzini S, Dondero F, Fenoglio S, Bona E, Jensen J, Viarengo A. 2008. A

"Wright-of-Evidence" Approach for the Integration of Environmental "Triad" Data to Assess Ecological Risk and Biological Vulnerability. Integrated Environmental Assessment and Management 4: 314-326.

Dawson JJC, Godsiffea EJ, Thompson IP, Ralebitso-Senior TK, Killhama KS, Paton GI. 2007. Application of biological indicators to assess recovery of hydrocarbon impacted soils. Soil Biology \& Biochemistry 39: 164-177.

Doni S, Macci C, Peruzzi E, Arenella M, Ceccanti B, Masciandaro G. 2012. In situ phytoremediation of a soil historically contaminated by metals, hydrocarbons and polychlorobiphenyls. J. Environ. Monit. 14: 1383-1390.

Egner H, Riehm H, Domingo WR. 1960. Untersuchungen über die chemische Bodenanalyse als Grundlage für die Beurteilung desNahrstoffzustandes der Boden, II: Chemische Extractionsmetoden zu Phosphor und Kaliumbestimmung. Kunliga Lantbrukshügskolans Annaler 26: 199-215.

Epelde L, Becerril J M, Hernóndez-Allica J, Barrutia O, Garbisu C. 2008b. Functional diversity as indicator of the recovery of soil health derived from Thlaspi caerulescens growth and metal phytoextraction. Applied Soil Ecology 39(3): 299-310.

Epelde L, Becerril JM, Barrutia O, Gonza lez-Oreja JA, Garbisu, C. 2010b. Interactions between plant and rhizosphere microbial communities in a metalliferous soil. Environmental Pollution 158: 1576-83. 
Revised manuscript 20140519

Epelde L, Becerril JM, Kowalchuk GA, Deng Y, Zhiu J, Garbisu C. 2010a. Impact of Metal Pollution and Thlaspi caerulescens Growth on Soil Microbial Communities. Applied and Environmental Microbiology 76 (23): 7843-7853.

Epelde L, Becerril JM, Mijangos I, Garbisu C. 2009. Evaluation of the efficiency of a phytostabilization process with biological indicators of soil health. Journal of Environmental Quality 38(5): 2041-2049.

Epelde L, Hernóndez-Allica J, Becerril JM, Blanco F, Garbisu C. 2008a. Effects of chelates on plants and soil microbial community: Comparison of EDTA and EDDS for lead phytoextraction. Science of The Total Environment 401(1-3): 21-28.

[FAO] Food and Agriculture Organization of the United Nations. 2006. Guidelines for soil description. 4th ed. Rome, Italy: Publishing Management Service.

Gelman A, Carlin JB, Stern HS, Rubin DB. 2004. Bayesian Data Analysis. 2nd ed. Chapman \& Hall/CRC.

Gugino BK, Idowu OJ, Schindelbeck RR, van Es HM, Wolfe DW, Moebius-Clune BN, Thies JE, Abawi GS. 2009. Cornell Soil Health Assessment Training Manual. 2nd ed. USA: Cornell Digital Print Services.

Idowu OJ, van Es HM, Abawi GS, Wolfe DW, Ball JI, Gugino B K, Moebius BN, Schindelbeck RR, Bilgili AV. 2008. Farmer-oriented assessment of soil quality using field, laboratory, and VNIR spectroscopy methods. Plant Soil 307: 243-253.

[ISO] International standard organization 10390. 2005. Soil quality - Determination of pH. [ISO] International standard organization 11263. 1994. Soil quality - Determination of phosphorus -- Spectrometric determination of phosphorus soluble in sodium hydrogen carbonate solution.

[ISO] International standard organization 11885. 1996. Water Quality - Determination of 33 elements by inductively coupled plasma atomic emission spectroscopy. 
Revised manuscript 20140519

[ISO] International Standard Organization 3310-2. 1999. Test sieves - Technical requirements and testing -- Part 2: Test sieves of perforated metal plate..

Jelusic M, Grcman H, Vodnik D, Suhadolc M, Lestan D. 2013. Functioning of metal contaminated garden soil after remediation. Environmental pollution 174: 63-70.

Karjalainen A-M, Kilpi-Koski J, Väisänen AO, Penttinen S, van Gestel CAM, Penttinen O-P. 2009. Ecological risk of an old wood impregnation mill: application of the triad approach. Integrated Environmental Assessment and Management 5(3): 379-389.

Karlen DL, Ditzler CA, Andrews SS. 2003. Soil quality: why and how? Geoderma 114: 145156.Landström Å, Östlund A-S. 2011. Choosing sustainable remediation alternatives at contaminated sites: Application and evaluation of a Multi-Criteria Analysis method. Master's Thesis 2011:110. Gothenburg, Sweden: Chalmers University of Technology. Available from: http://www.renaremark.se/filarkiv/exjobb/2011/Asa_Ann-Sofie.pdf

Lehmann A, David S, Stahr K. 2008. TUSEC-A manual for the evaluation of Natural Soils and AnthropogenicUrban Soils. Bilingual edition. Stuttgart, Germany: Hohenheimer Bodenkundliche Hefte. 224 p.

Makino T, Kamiya T, Takano H, Itou T, Sekiya N, Sasaki K, Maejima Y, Sugahara K. 2007. Remediation of cadmium-contaminated paddy soils by washing with calcium chloride: Verification of on-site washing. Environmental Pollution 147(1): 112-119.

McIntosh MF. 1969. Bray and Morgan soil test instractants modified for testing acid soils from different parent materials. Agron J 61: 259-265.

NCC Teknik. 2000. Resultat-Översiktlig markmiljörundersökning inom Kvilleverkstaden 738:627. Geoteknik PM 03. Göteborg, Sverige: NCC Teknik.

NCC Teknik. 2010. Saneringsanmälan för Trädgården 1:124. Göteborg, Sverige: NCC Teknik. 
Osztoics E, Sardi K, Csatho P, Radimszky L. 2011. Characterization of soil P-supplying ability in terms of agronomy and environment protection. Agrokemia es talajtan 60: 175190.

Pautler MC, Sims JTh. 2000. Relationships Between Soil Test Phosphorus, Soluble Phosphorus, and Phosphorus Saturation in Delaware Soils. Soil Sci Soc Am J 64:765773.

Pazos M, Plaza A, Martin M, Lobo MC. 2012. The impact of electrokinetic treatment on a loamy-sand soil properties. Chemical Engineering Journal 183: 231-237.

Postuma L, Suter GW. 2011. Ecological risk assessment of diffuse and local soil contamination using species sensitivity distribution. In: Swartjes, F.A., editor. Dealing with contaminated sites. Springer Science +Business Media B.V, p. 625-692.

Rosén L, Back P-E, Norrman J, Söderqvist T, Norberg T, Volchko Y, Brinkhoff P, Norin M, Bergknut M, Döberl G. 2013. SCORE: Multi-Criteria Analysis (MCA) for Sustainability Appraisal of Remedial Alternatives. In: Proceedings of the Second International Symposium on Bioremediation and Sustainable Environmental Technologies; June 1013, 2013; Jacksonville, Florida, USA. Available from: https://projects.battelle.org/bioremediation-symposium/2013\%20Bio\%20Proceedings/E25 Ppr.pdf

Schindelbeck R, van Es HM, Abawi GS, Wolfe DW, Whitlow TL, Gugino BK, Idowu OJ, Moebius-Clune BN. 2008. Comprehensive assessment of soil quality for landscape and urban management. Landscape and Urban Planning 88: 73-80.

Semenzin E, Critto A, Marcomini A. 2009. Ecosystem impairment evaluation on biodiversity and functional diversity for contaminated soil assessment. Integrated Environmental Assessment and Management 5(3): 399 - 413. 
Revised manuscript 20140519

Sharifi M, Zebarth BJ, Burton DL, Grant CA, Bittman, S, Drury CF, McConkey BG, Ziadi N. 2008. Response of potentially mineralizable soil nitrogen and indices of nitrogen availability to tillage system. Soil Science Society of America Journal 72: 1124-1131.

Sorvari J, Schultz E, Haimi J. 2013. Assessment of Ecological Risks at Former Landfill Site Using TRIAD Procedure and Multicriteria Analysis. Risk Analysis 33(2): 203-219. SS 02 8310. 1993. P-AL metoden. Swedish Standards Institute.

SS-EN 12879. 2000. Karaktärisering av slam - Bestämning av torrsubstansförlust vid upphettning. Swedish Standards Institute.

Swartjes FA, Rutgers M, Lijzen JPA, Janssen PJCM, Otte PF, Wintersen A, Brand E, Posthuma L. 2012. State of the art of contaminated site management in The Netherlands: Policy framework and risk assessment tools. Science of the Total Environment 427-428: $1-10$.

Sweco 2009. Fastigheten trädgården 1:124, Kvarnbyparken, Mölndal. Fördjupad riskbedömning inklusive beräkning av platsspecifika riktvärden. Göteborg, Sverige: Sweco.

Swedish EPA. 1996. Development of generic guideline values. Models and data used for generic guideline values of contaminated soil in Sweden. Stockholm, Sweden: Swedish EPA. Report 4639.

Swedish EPA. 1999. Bedömningsgrunder för miljökvalitet. Skogslandskapet. Sverige: Naturvårdsverket. Rapport 4917.

van Herwijnen R, Al-Tabbaa A, Hutchings TR, Moffat AJ, Ouki SK, Johns ML.2007. The Impact of Waste Compost-Based Soil Amendments on the Leaching Behavior of a Heavy Metal Contaminated Soil. Environmental engineering science 24 (7): 897-904. 
Volchko Y, Norrman J, Bergknut M, Rosén L, Söderqvist T. 2013. Incorporating the Soil Function Concept into Sustainability Appraisal of Remediation Alternatives. The Journal of Environmental Management 129: 367-376.

Volchko Y, Norrman J, Rosén L, Bergknut M, Josefsson S, Söderqvist T, Norberg T, Wiberg K, Tysklind M. 2014. Using soil function evaluation in multi criteria decision analysis for sustainability appraisal of remediation alternatives. Science of the Total Environment 485-486: 758-791.

Volchko Y. 2013. SF Box - A tool for evaluating ecological soil functions in remediation projects. Gothenburg, Sweden: Chalmers Reproservice. Report 2013:1. Available from: http://publications.lib.chalmers.se/records/fulltext/183250/183250.pdf

\section{LIST OF FIGURES}

Figure 1. A generic framework for soil function assessment (modified after Karlen et al. 2003). The dotted box corresponds to operations carried out in the SF Box module.

Figure 2. The overall input/output flow in SF Box. BD: bulk density. ST: soil texture. OM: organic matter content. $\mathrm{NH}_{4}-\mathrm{N}$ : potentially mineralizable nitrogen. CM: content of coarse material. AW: available water capacity. P: available phosphorus. AW_Score, OM_Score, CM_Score, pH_Score, N_Score, P_Score - the computed sub-scores for $\mathrm{AW}, \mathrm{OM}, \mathrm{CM}, \mathrm{pH}, \mathrm{NH}_{4}-\overline{\mathrm{N}}$ and $\mathrm{P}$ respectively.

Figure 3. Scoring functions used for transforming the measured values of SQIs into sub-scores between 0 and 1 . $\mathrm{CM}$ : content of coarse material. AW: available water capacity. OM: organic matter content. $\mathrm{NH}_{4}-\mathrm{N}$ : ammonium determined with the distillation method. AL-P: available phosphorus.

Figure 4. Results of soil function assessment for the soil at Hexion to a depth of 0-20cm (a) and 20-50cm (b). CM: content of coarse material. OM: organic matter content. AW: available water capacity. $\mathrm{NH}_{4}-\mathrm{N}$ : ammonium determined with the distillation method. P: available phosphorus.

Figure 5. Results of soil function assessment for the soil at Kvillebäcken to a depth of 0-20cm (a) and 20-50cm (b). CM: content of coarse material. OM: organic matter content. AW: available water capacity. $\mathrm{NH}_{4}-\mathrm{N}$ : ammonium determined with the distillation method. P: available phosphorus.

Figure 6. Histogram showing the mean, the 5- and the 95-persentales of simulated soil quality index for the upper $20 \mathrm{~cm}$ soil layers at Hexion and Kvillebäcken. The arithmetic (A) mean and the geometric (G) mean were used to aggregate the sub-scores. The dotted area corresponds to a medium soil performance. 
Revised 20140519

Table 1. Key criteria of the updated MCDA framework by Rosén et al. (2013)

\begin{tabular}{|l|l|l|}
\hline Environmental domain & Socio-cultural domain & \multirow{2}{*}{ Economic domain } \\
\hline Soil & Local environmental quality & \\
Flora and fauna & and amenity & \\
\hline Groundwater & Cultural heritage & \multirow{2}{*}{ Social profitability } \\
\hline Surface water & Equity & \\
\hline Sediment & Health and safety & \\
\hline Air & Local participation & \\
\hline $\begin{array}{l}\text { Non-renewable natural } \\
\text { resources }\end{array}$ & Local acceptance & \\
\hline Non-recyclable waste & & \\
\hline
\end{tabular}


Revised 20140519

Table 2. The proposed minimum data set for soil function assessment in remediation projects (after Vo Soil Quality Indicators (SQIs)

Physical

Soil texture (ST)

Content of coarse material* $(\mathrm{CM})$

Available water capacity (AW)

Biological

Organic matter content (OM)

Potentially mineralizable nitrogen $\left(\mathrm{NH}_{4}-\mathrm{N}\right)$

Chemical

$\mathrm{pH}$

Available phosphorus (P)

$*$ The coarse fragment $(\varnothing>2 \mathrm{~mm})$ content. 
lchko et al. 2014) 
Revised 20140519

Table 3. Sources of data for determination of scoring functions in SF Box (modified after Volchko 2013)

\begin{tabular}{|c|c|c|c|}
\hline $\begin{array}{l}\text { Sub- } \\
\text { scores }\end{array}$ & Analysis Method & $\begin{array}{l}\text { Scoring } \\
\text { function } \\
\text { type }\end{array}$ & Source of data/comment \\
\hline $\mathrm{CM}$ & $\begin{array}{l}\text { Sieving } \\
(\text { ISO 3310-2) }\end{array}$ & $\begin{array}{l}\text { "Less is } \\
\text { better" }\end{array}$ & $\begin{array}{l}\text { The threshold value (i.e. a sub-score of } 0.3 \text { ) for soil } \\
\text { functions associated with primary production is a content } \\
\text { of coarse material equal to } 35 \% \text {. The coarse fraction } \\
\text { content less than } 15 \% \text { is scored higher than } 0.7 \text { (Craul } \\
\text { and Craul 2006). }\end{array}$ \\
\hline AW & $\begin{array}{l}\text { Detrmined inderactly } \\
\text { using a relation } \\
\text { between soil texture, } \\
\text { organic matter and } \\
\text { bulk density } \\
(\text { Lehmann et al. } 2008) \\
\end{array}$ & $\begin{array}{l}\text { "More is } \\
\text { better" }\end{array}$ & Gugino et al. (2009) \\
\hline $\mathrm{OM}$ & $\begin{array}{l}\text { Loss on ignition } \\
\text { (SS-EN 12879) }\end{array}$ & $\begin{array}{l}\text { "More is } \\
\text { better" }\end{array}$ & Gugino et al. (2009) \\
\hline \multirow{2}{*}{$\mathrm{NH}_{4}-\mathrm{N}$} & $\begin{array}{l}\text { Anaerobic incubation } \\
\text { (Gugino et al. 2009) }\end{array}$ & \multirow{2}{*}{$\begin{array}{l}\text { "More is } \\
\text { better" }\end{array}$} & Gugino et al. (2009) \\
\hline & $\begin{array}{l}\text { Distillation } \\
\text { (APHA 1992) }\end{array}$ & & $\begin{array}{l}\text { The scoring function is based on the estimated } \\
\text { representative values provided by a certified laboratory. }\end{array}$ \\
\hline $\mathrm{pH}$ & $\begin{array}{l}\mathrm{pH}\left(\mathrm{H}_{2} \mathrm{O}\right) \\
(\mathrm{ISO} 10390)\end{array}$ & “Optimum" & $\begin{array}{l}\text { The scoring curves for vegetation favoring neutral and } \\
\text { acidic pH are based on data provided by Gugino et al. } \\
\text { (2009) and Swedish EPA (1999) respectively. }\end{array}$ \\
\hline \multirow{4}{*}{$\mathrm{P}$} & $\begin{array}{l}\text { Morgan-P } \\
(\text { McIntosh 1969) } \\
\end{array}$ & \multirow{4}{*}{ “Optimum" } & Gugino et al. (2009) \\
\hline & $\begin{array}{l}\text { Olsen-P } \\
(\text { ISO 11263) } \\
\end{array}$ & & \multirow{3}{*}{ 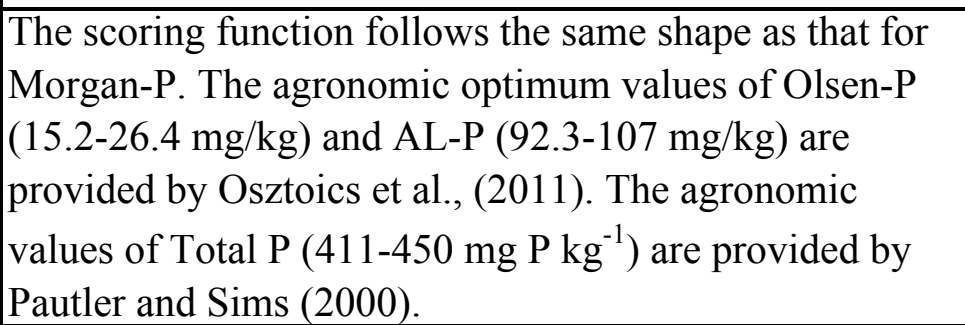 } \\
\hline & $\begin{array}{l}\text { AL-P } \\
(\text { Egner et al. 1960) }\end{array}$ & & \\
\hline & $\begin{array}{l}\text { Total P } \\
(\text { ISO 11885) } \\
\end{array}$ & & \\
\hline
\end{tabular}


Revised 20140519

Table 4. Correspondence between soil classes, soil performances and a soil quality index (modi

\begin{tabular}{|c|l|l|}
\hline Soil class & Soil performance & Soil quality index \\
\hline 1 & Very good & $>0.85$ \\
\hline 2 & Good & $0.70-0.85$ \\
\hline 3 & Medium & $0.55-0.69$ \\
\hline 4 & Poor & $0.40-0.54$ \\
\hline 5 & Very poor & $<0.40$ \\
\hline
\end{tabular}


fied after Gugino et al. 2009; Volchko 2013; Volchko et al. 2014) 


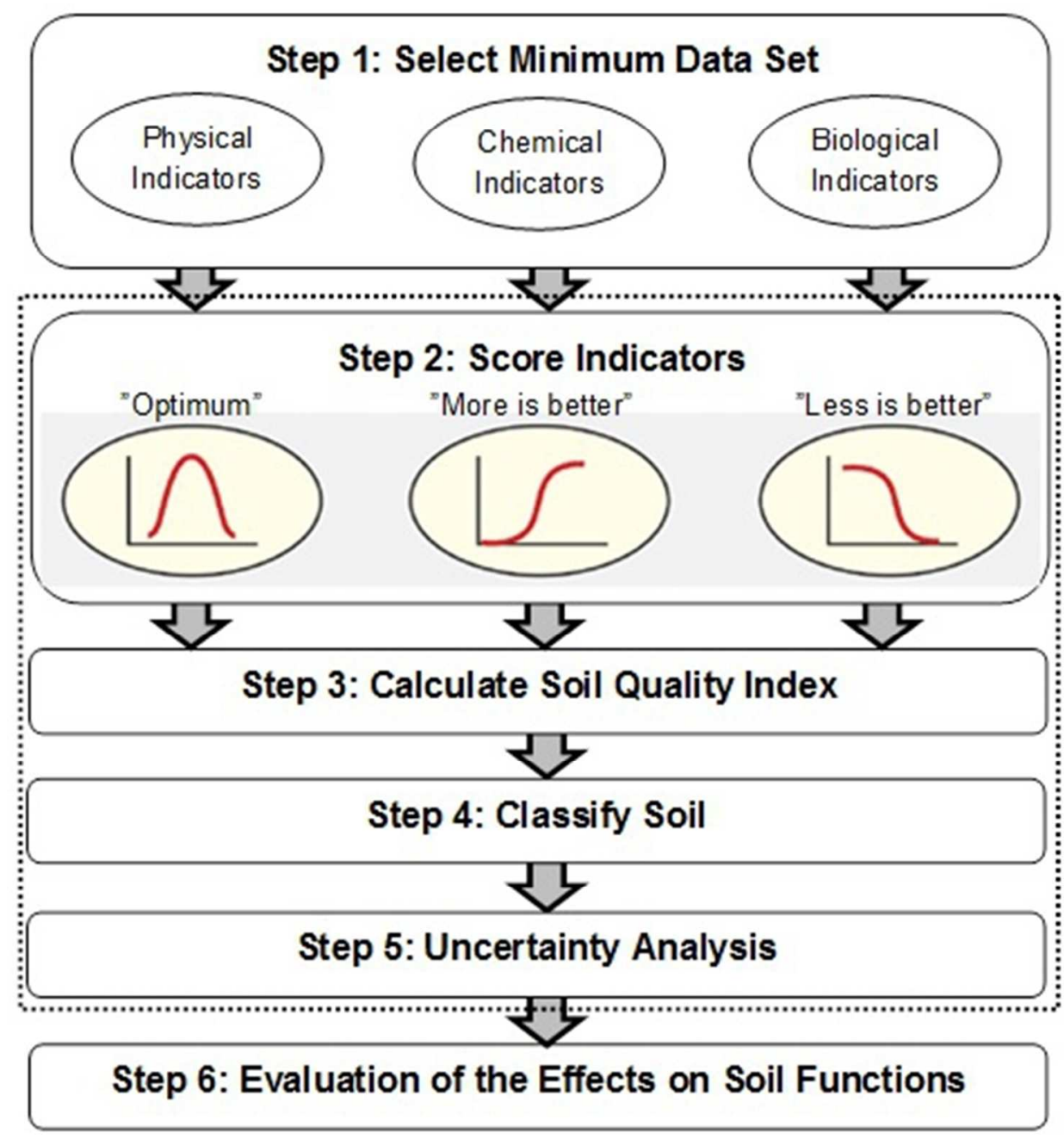

$125 \times 133 \mathrm{~mm}(96 \times 96$ DPI $)$ 


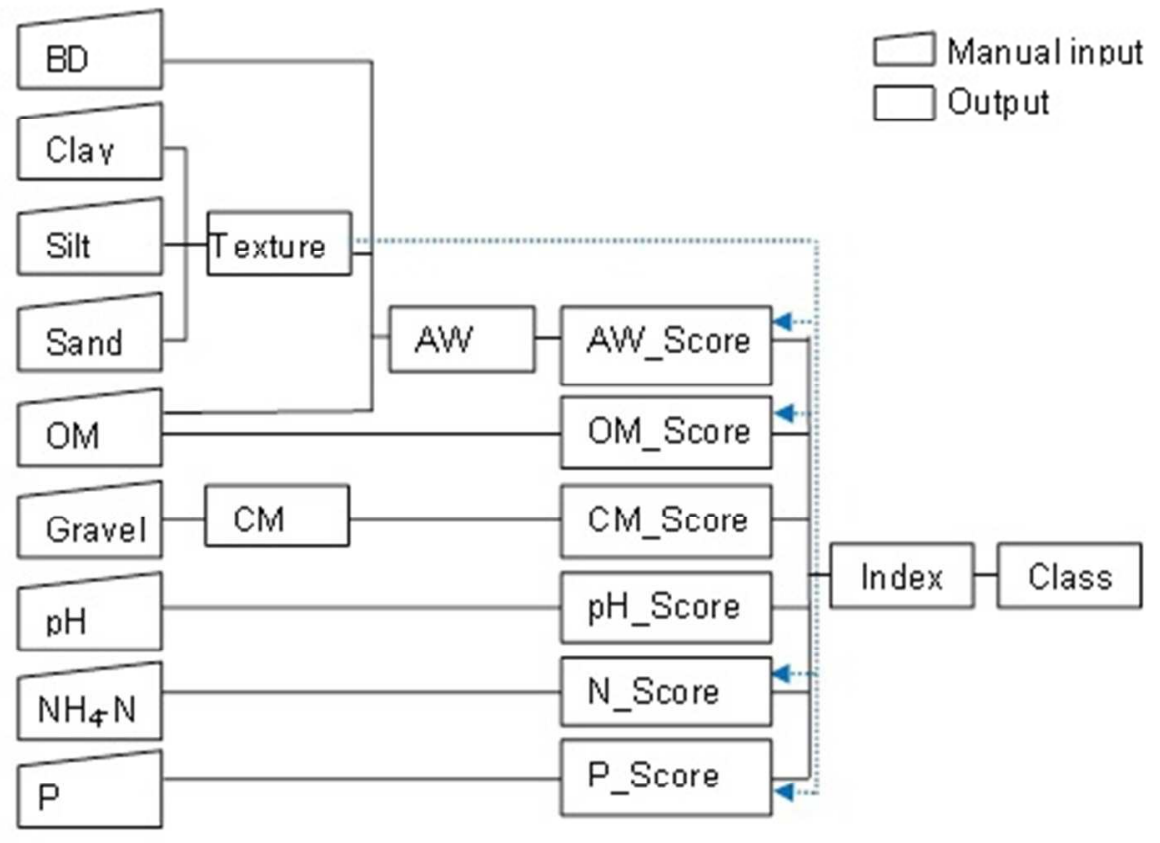

$124 \times 94 \mathrm{~mm}(96 \times 96 \mathrm{DPI})$ 


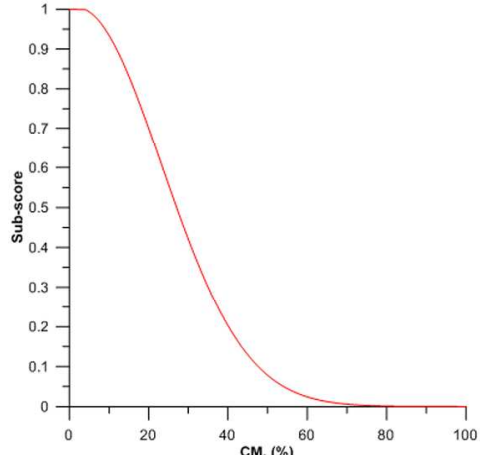

(a)

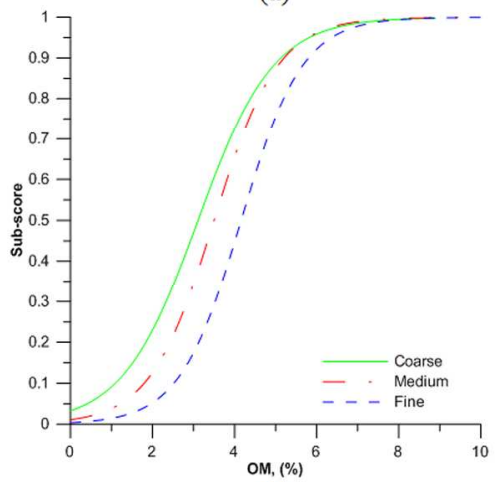

(c)

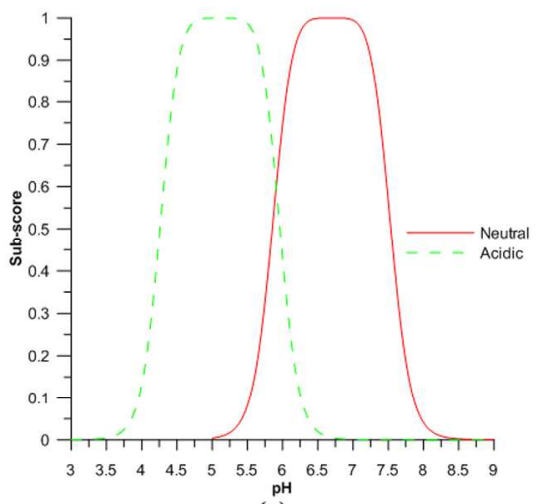

(e)

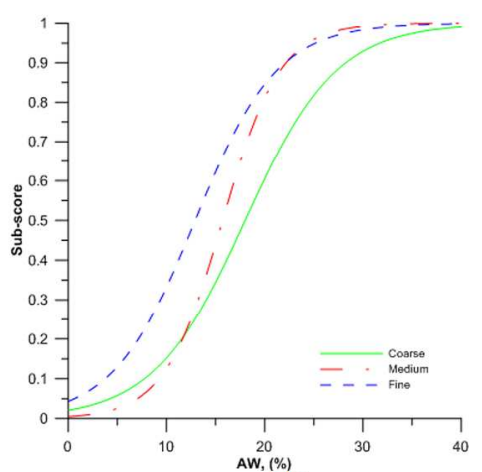

(b)

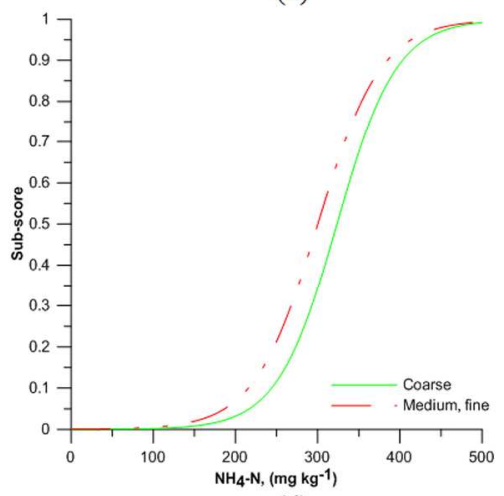

(d)

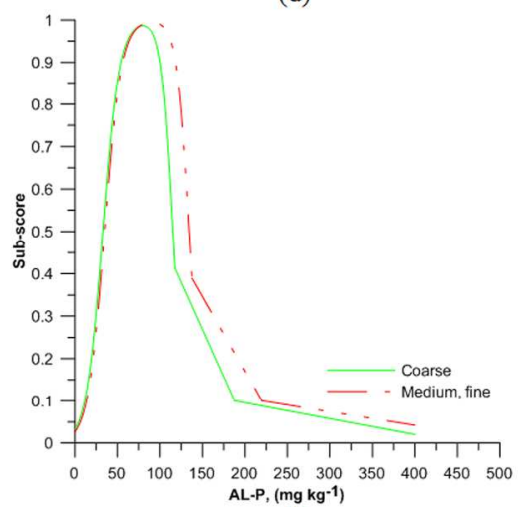

(f)

$217 \times 306 \mathrm{~mm}(300 \times 300$ DPI $)$ 


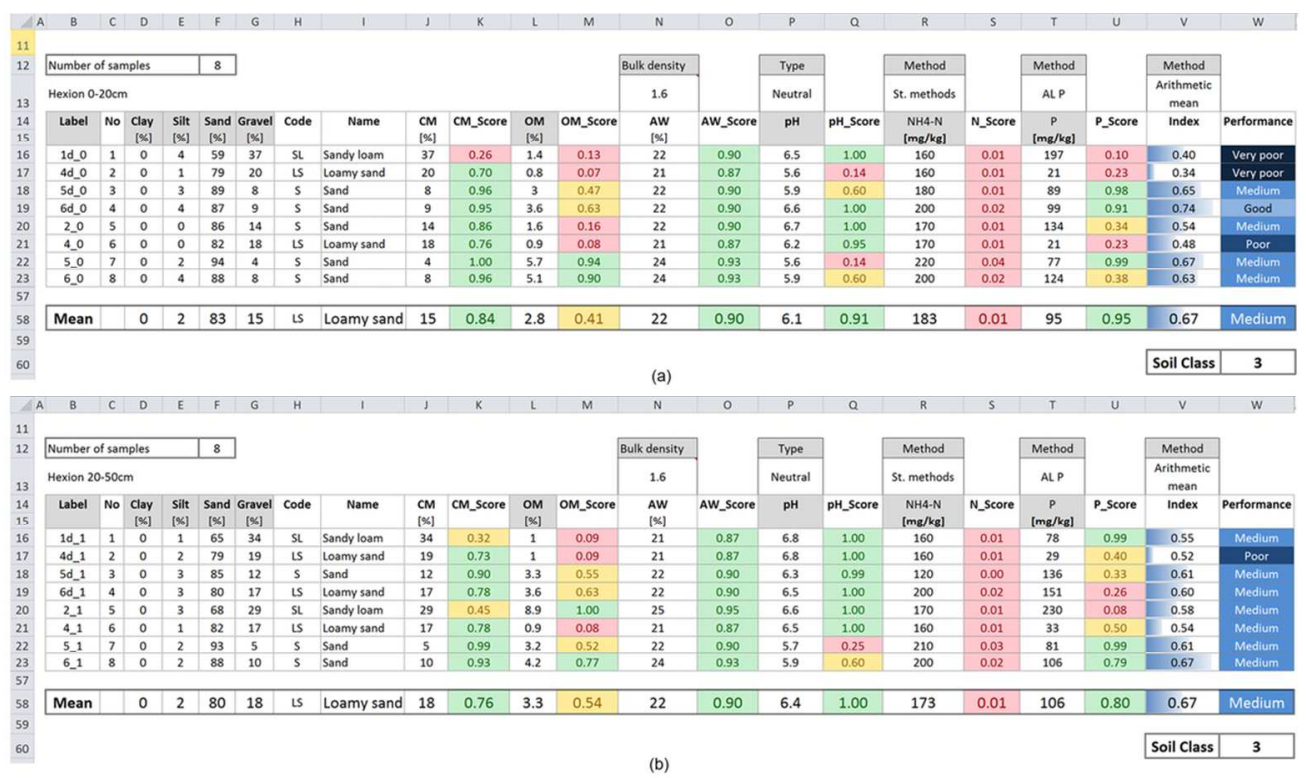

$99 \times 58 \mathrm{~mm}(300 \times 300$ DPI $)$ 


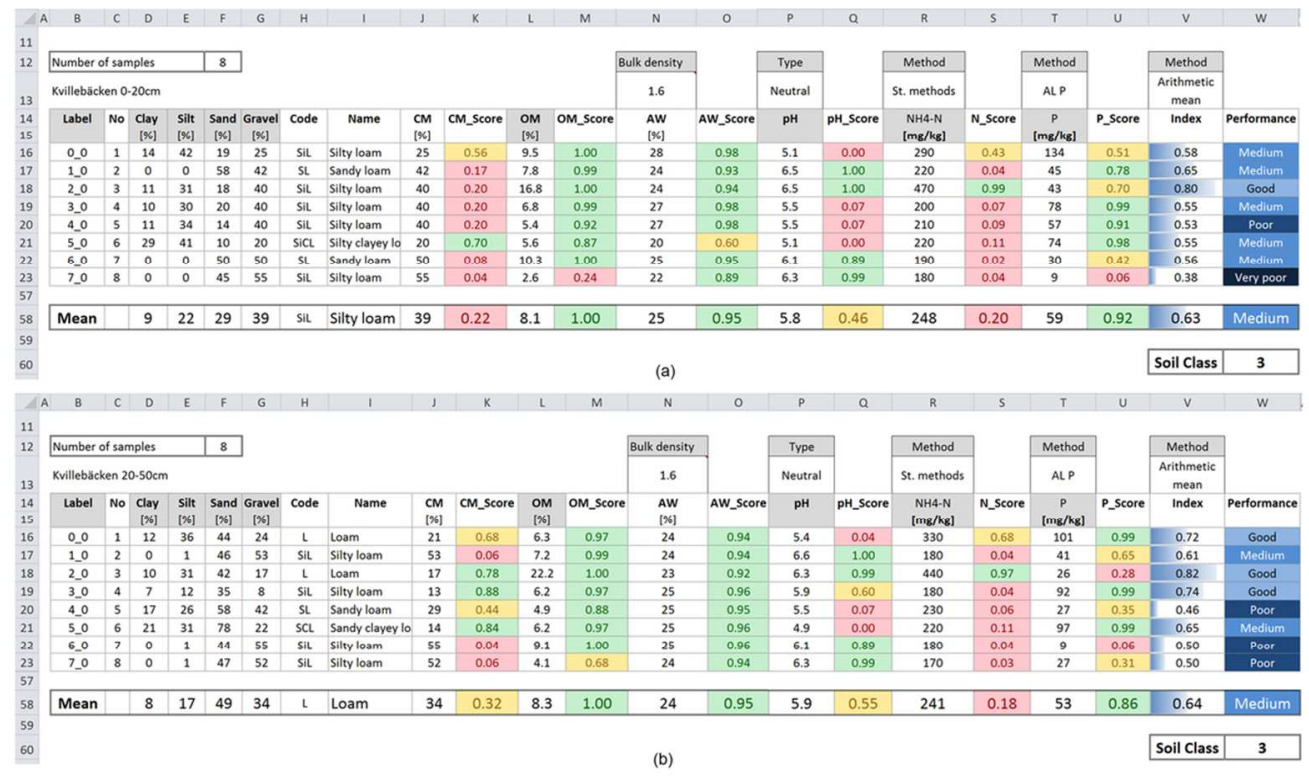

$99 \times 58 \mathrm{~mm}(300 \times 300 \mathrm{DPI})$ 


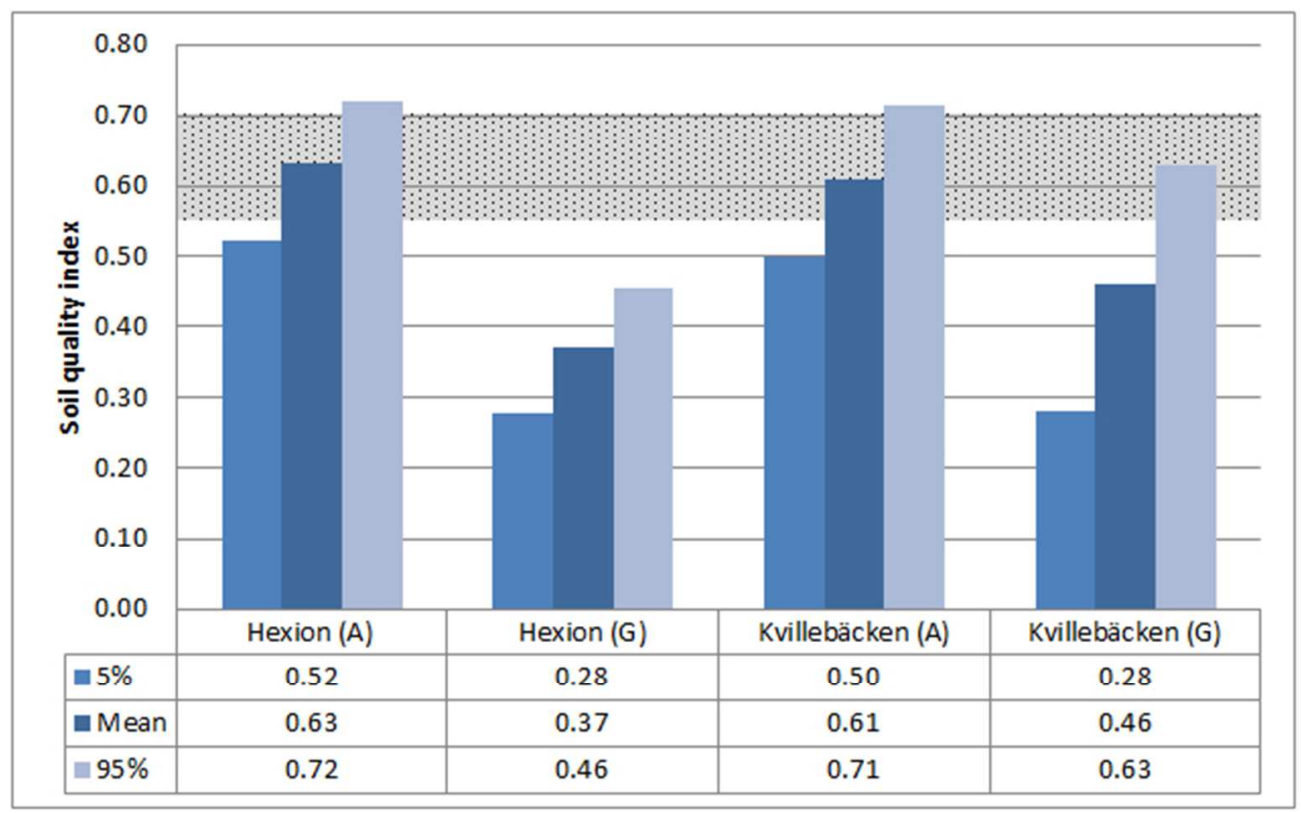

$169 \times 106 \mathrm{~mm}(96 \times 96 \mathrm{DPI})$ 